\title{
The Pharmacist's Guide to Evidence-Based Medicine for Clinical Decision Making
}

Bryant PJ, Pace HA. American Society of Health-System Pharmacists, Bethesda, Maryland, 2009. 198 pp. ISBN 978-1-58528-177-0. ASHP members US\$39, nonmembers US\$49.

In the 1990s, the term "evidence-based medicine" (EBM) was introduced to the lexicon of most health care professionals by pioneers such as David Sackett and Gordon Guyatt. This paradigm shift in the clinical decision-making process incorporated not only a clinician's experience, but also patients' values and relevant evidence as a way to improve patient care. ${ }^{1}$

The purpose of the book under review is to describe for pharmacy students and practitioners a 5-step process for clinical decision-making. It is meant to be an easily digested "how to" guide for pharmacists. Interestingly, its contents are based on a required course in the Doctor of Pharmacy program at the University of Missouri-Kansas City. The book is arranged in 3 sections: interpreting trial data, the 5-step EBM process, and applying the EBM process to patients. Peppered throughout the book are concise tips, called "key ideas", which remind the reader of important points to consider or places to find information.

Essentially, this guide does provide a basic level of information about the EBM process and its application to patient care. It outlines a strategy to identify, obtain, evaluate, and assess the literature so as to make informed clinical decisions. But readers should not expect this text to be a comprehensive EBM resource like Evidence-Based Medicine: How to Practice and Teach EBM, now in its third edition (Churchill-Livingstone, 2005), or the Journal of the American Medical Association users' guides, which were published in a series of articles in the journal (starting in November 1992) and are now maintained online by the Centre for Health Evidence (http://www.cche.net/usersguides/ main.asp).

This text has 10 well-written chapters appearing in a logical sequence. There is also a helpful glossary of commonly used EBM terms. In addition, a brief (4-page) section in the book entitled "EBM tools" has some useful tables and forms. Of special note, there is a chapter devoted to applying EBM principles to therapeutic decisions about dietary supplements.

According to the authors, "the busy practitioner" could "read through the text in an evening or two and immediately apply the 5 step EBM process to his or her practice setting". Although it may be possible to apply parts of the process immediately, I think it would be unrealistic for those unfamiliar with EBM concepts to apply them on the basis of this resource alone. Some limitations of this guide are the limited information on trial design and biostatistics. Although the section on searching the literature would be useful for some, I don't believe the suggested approach is the most efficient or fruitful. I would have also liked to see more references to other available EBM resources. Strengths include the concise, easily comprehensible nature of the book and the chapters about asking clinical questions and applying trial results to patients. 
In summary, this guide provides some useful, basic information on EBM for pharmacy practitioners. It would be a good resource for those who want a quick refresher of EBM concepts.

\section{Reference}

1. Sackett, DL, Rosenberg WC, Gray JAM, Haynes RB, Richardson WS. Evidence based medicine: what it is and what it isn't. BMJ 1996;312(7023):71-72.
Adil Virani, BSc(Pharm), PharmD, FCSHP

Pharmacy Services

Fraser Health Authority

Langley, British Columbia

University of British Columbia

Vancouver, British Columbia

\section{ON THE FRONT COVER}

\section{Ross Memorial Hospital, Lindsay, Ontario}

Located in Lindsay, Ontario, Ross Memorial Hospital is an active community hospital, with a capacity of 218 beds and about 44000 visits to its

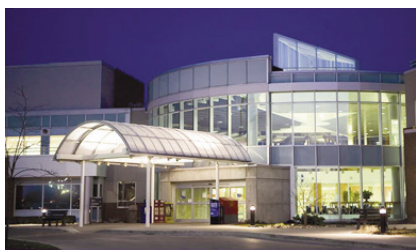
Emergency Department each year.

The hospital's vision statement, "Exceptional people committed to providing exceptional care," is reflected by the staff members of its innovative Pharmacy Department, who continue to find ways to expand services, despite pharmacist shortages. Pharmacy technicians perform all order entry, prepare sterile products in a clean room that meets USP <797> standards, and check each other's dispensing. The technicians also conduct best possible medication histories for emergency admissions and for patients admitted for elective orthopedic surgery. A telepharmacist reviews and verifies all orders received on weekdays (Monday to Friday). This allows the on-site pharmacist to be involved in clinical patient care and medication safety activities.

The team's skill is only outdone by its enthusiasm, which extends beyond the department - the Pharmacy team participates in both hospital and community events.

Photo credit: Ridout Photography (www.ridoutphotography.com); Canon 5D Mark II camera.

The CJHP would be pleased to consider photographs featuring Canadian scenery taken by CSHP members for use on the front cover of the journal. If you would like to submit a photograph, please send an electronic copy (minimum resolution $300 \mathrm{dpi}$ ) to Sonya Heggart at sheggart@cshp.ca. 